\title{
ENVIRONMENTAL ASPECTS OF GRID CONNECTED POWER ELECTRONIC CONVERTERS CONTROL
}

\section{Tomasz Chmielewski ${ }^{1}$}

1 Electrical Engineering and Computer Science Faculty, Lublin University of Technology, Nadbystrzycka 38A, 20-618 Lublin, Poland, e-mail: t.chmielewski@pollub.pl

Received: 2016.12 .02

Accepted: 2017.01.07 Published: 2017.03.01

\begin{abstract}
This paper presents an unconventional view on power electronic converters control as an important factor in environmental protection. Two distinct features that are provided by the control system, namely harmonics elimination and Fault Ride-Through are addressed herein. The paper provides the discussion on how well designed and robust power converter control can influence the environment in a positive way. One of the shortcomings of power converters is emission of current harmonics which results in supply voltage distortion. The appropriate control minimizes the harmonics content which leads to energy losses reduction, especially in power transformers cores. Fault ride-through is an ability of power converter to remain connected and operating in a grid where the fault occurred. It is of paramount importance for integration of large power renewable energy sources. Shutting down e.g. large wind farm would result in engaging the conventional power plants to fill in the energy production gap.
\end{abstract}

Keywords: converters, energy, control system, power transformers

\section{INTRODUCTION}

The power converters based on semiconductor devices that operate in a switch mode are widely used for variety of applications, especially involving integration the renewable energy sources, flexible power supplies and battery chargers [Jarzyna 2011, Yaramasu et al. 2015]. The examples of modern power electronic converters applications in power systems is presented in Figure 1. As can be observed, as a result of rapid power electronic converter development, it is not only possible to produce and utilize the electrical energy more efficiently but also to transmit it using high voltage direct current (HVDC) technology over large distances with lower losses, as compared to the traditional alternating current (AC) systems. The HVDC transmission has also got another, very positive effect on environment, which is more straightforward than limited energy losses - HVDC transmission lines can be either put under ground as cables or they take significantly less space when implemented as overhead lines.
For this reason, not only the natural terrain degradation during construction stage is less severe but also resources required for that purpose are significantly reduced. This is beneficial both in environmental, as well as economical terms. Therefore, due to large penetration, the impact of power converters operation on the grid is rather noticeable. Hence, there are numerous energy quality standards that each of grid connected power converter must comply with (depending on its rated power). International standardization committees such as The International Electrotechnical Commission (IEC), The Institute of Electrical and Electronics Engineers (IEEE), CEN and CENELEC (EN standards) work towards regulations that provide minimum requirements regarding continuity of service, voltage magnitude variations, voltage and current transients and finally current harmonics emission and voltage harmonics content. Each of above-mentioned problems should be addressed at the design stage of the power converter. Such system coordination should be channelled towards elimination or at least limitation 

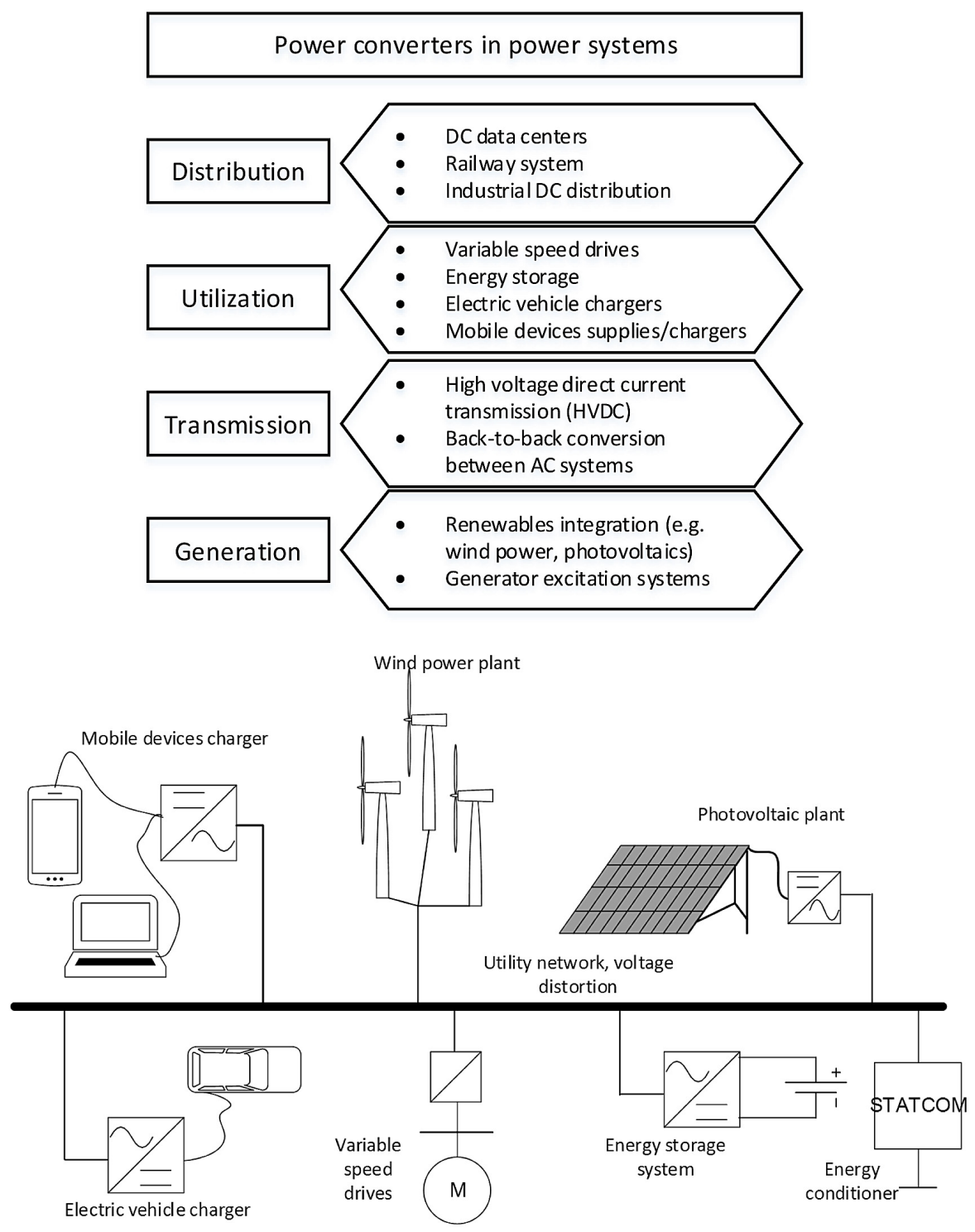

Figure 1. Grid application of power electronic converters

of some of undesired effects of power converter operation (e.g. harmonics, ability to withstand voltage variations), [IEEE 2013].

It is noteworthy that regardless of their application, with modern power electronic converters it is possible to obtain high flexibility of output parameters thanks to appropriate topology, but mainly owing to well-designed control algorithms. Appropriate control algorithm ensure not only the realisation of application target, but can also serve as an aid for achieving acceptable limits of for example harmonics emission or become indispensable when it comes to operation in faulty grid conditions (Fault Ride-Through), which result in a voltage dip [Zieliński et al. 2015]. Over recent years, both topics have been objects of intensive research that produced various control techniques able to limit the current harmonics (and eventually voltage distortion), as well as to act according to grid operator requirements during faults [Timbus et al. 2006].

The Fault Ride-Through (FRT) techniques differ for various applications (photovoltaics, wind power). For example, in the case of wind power, the FRT method will strongly depend on the generator type, some of which may require additional equipment e.g. energy storage, crowbars. Regardless of the FRT technique, the result should be compliant with local grid code.

This papers focuses mainly on the effect of energy losses which is amplified by the presence of harmonics in current and voltage. Secondly, the topic related to reliability of energy delivery from renewables integrated via power converters is addressed. In both cases, it is aimed to demonstrate that the accordingly coordinated control 
system may lead to limitation of losses, as well as possible reduction of fossil fuels consumption and related pollution. The paper provides simulation and calculation results, as well as the discussion on the proposed topics.

\section{HARMONICS IN POWER SYSTEMS}

Due to fact that the power electronic converters operate in switch mode (the conversion of energy is done by means of blocking and unblocking of solid state switches of the device), the generation of the higher current harmonics is inevitable. However, not only such devices are sources of harmonics in power systems some other examples are nonlinear loads such as arc furnaces, welders or systems that can generate voltages with frequencies other than network frequency or absorb non-sinusoidal current. Distorted periodic waveform can be represented in a simple way as a sum of fundamental component and harmonics as in equation (1) [IEEE 2013]. The common way to describe the level of harmonic distortion in a signal is Total Harmonic Distortion factor expressed (THD) described by (2). The plotted waveforms of voltage and current containing harmonics that results in voltage contamination is pressed in Figure 2. Waveforms of current and voltage measured behind the inductance have significant and visible distortion. As can be observed, the result- ing harmonic level expressed in signal THD is higher in voltage than in current (which in this case is the stimulus for harmonics emission). This is caused by presence of inductance in a system. The voltage drop across the inductive element is crucial for voltage stability at the point of connection for loads or generation that cause flow of distorted current. This inductance represents equivalent of the power system in a most simple way. The higher the equivalent inductance is (due to e.g. longer lines, more power transformers), the lower the voltage stability at a given point. This means that in the network with high equivalent inductance (so called "weak network") the current that contains harmonics will create unfavourable voltage conditions that will affect other equipment connected to this particular network. Hence, it is of paramount importance to keep the harmonic content in currents as low as possible.

$$
\begin{gathered}
y=f(x)=a_{0}+\sum_{n=1}^{\infty} A_{n} \sin \left(n \cdot \omega t+\varphi_{n}\right) \\
T H D=100 \cdot \sqrt{\sum_{n=2}^{\infty}\left(\frac{A_{n}}{A_{1}}\right)^{2}}
\end{gathered}
$$

where: $n-$ harmonic order $(n=1$ is the fundamental component $a_{0}$ - possible offset $y$-instantaneous value of distorted wave
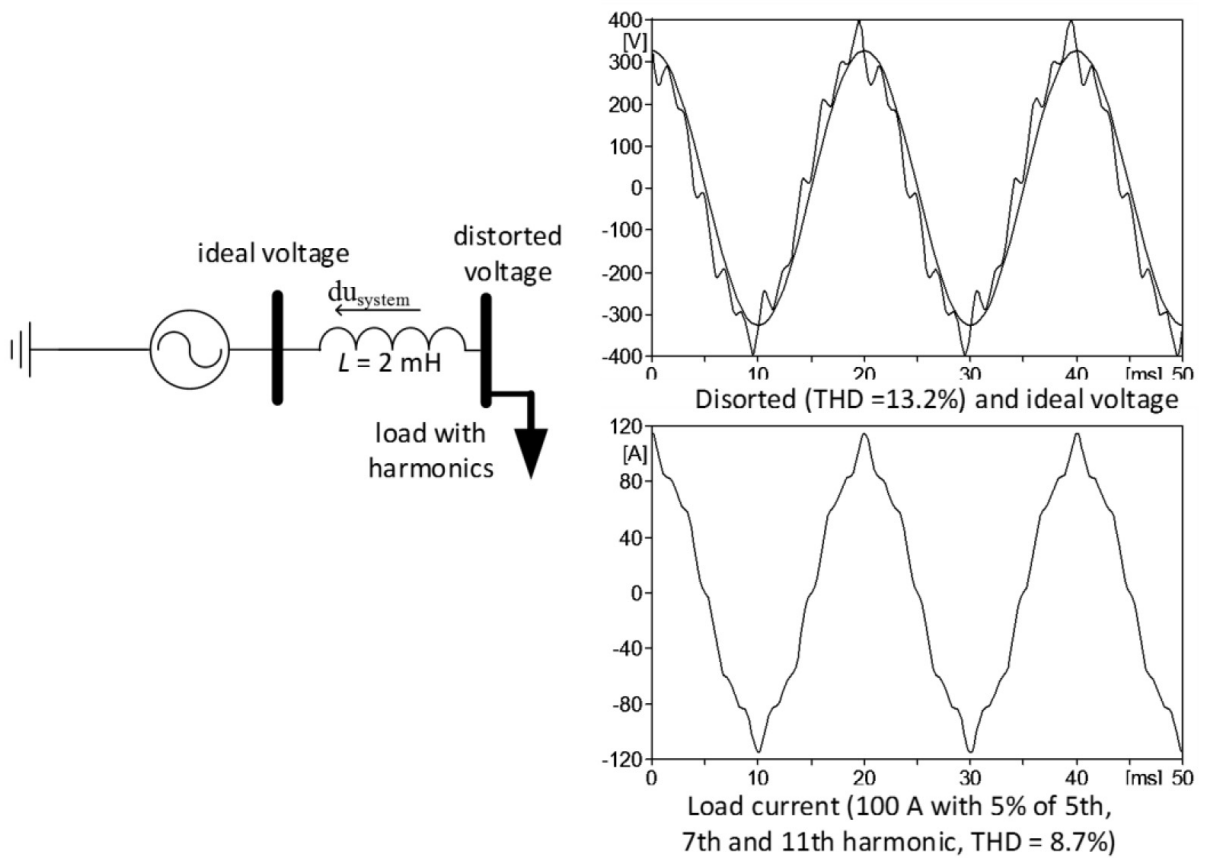

Figure 2. Example of distorted current and resulting harmonics in voltage of simple electrical system 
$A_{n}-$ peak value of nth harmonic component

$A_{1}$ - peak value of the fundamental component

$\omega$ - grid rated angular frequency

$t$ - time

$\varphi_{n}$ - phase angle of nth harmonic component at $t=0$

$n$ - harmonic order ( $n=1$ is the fundamental component

$a_{0}-$ possible offset

$y$ - instantaneous value of distorted wave

$A_{n}$ - peak value of $n$th harmonic component

$\omega$ - grid rated angular frequency

$t$ - time

$\varphi_{n}$ - phase angle of nth harmonic component at $t=0$

Regardless of the source of harmonics emission, the effect is similar i.e. distortion of sinusoidal voltage and current. Harmonics presence both in voltage and current results in many adverse effects on various equipment. Depending on particular apparatus type, those can be for example increased losses and heating, interference with adjacent communication equipment. In the case of rotating machines, the harmonics in current and voltage lead to increased iron and copper losses, higher noise emission, mechanical torque oscillations, cogging phenomena (refusal to start smoothly) or crawling (high slip) in induction motors. Similar effect can be observed for transformers (increased stray, no-load and copper losses, increased audible noise, necessity for increased transformer rating and related material usage). For cables, the presence of harmonics may consequently lead to resonance effects, increased heating and losses due to skin effect and, as a result - need for larger cable cross-section. Resonance and losses are also of a concern for capacitors (e.g. filters, reactive power compensation systems). Remaining equipment that is affected by presence of voltage and current harmonics in terms of additional losses and proper operation are electronic equipment, metering, switchgear and relaying. [IEEE 2013, Jagieła 2011].

\section{CONTROL ALGORITHMS AND THEIR IMPACT ON HARMONICS EMISSION}

The typical power converter used either as a supply or to couple distributed generation comprises number of semiconductor devices operating in a switch mode. Proper sequence of open/ close operation of all switches ensures the desired output. The process is controlled by a control system that analyses the output conditions and adjusts the operation of the power converter accordingly to the reference. The control system is then essential part of conversion process. Among all of its tasks, the control system has to be implemented in a way that it provides low disturbance rate at the output signal. Hence, the limitation of harmonics should be also studied as it could be influenced by the control. In this paper, in order to exemplify how the output harmonics vary simply due to the modified control structure, a set of simulations was run on a typical two-level voltage source inverter connected to the grid, which can serve, for instance, as a photovoltaic plant integration link to the utility grid. The energy source that generates DC power has to be coupled via properly controlled inverter which is able to transform the $\mathrm{DC}$ power into $\mathrm{AC}$ power with desired parameters and quality. Both control systems operate in voltage oriented arrangement

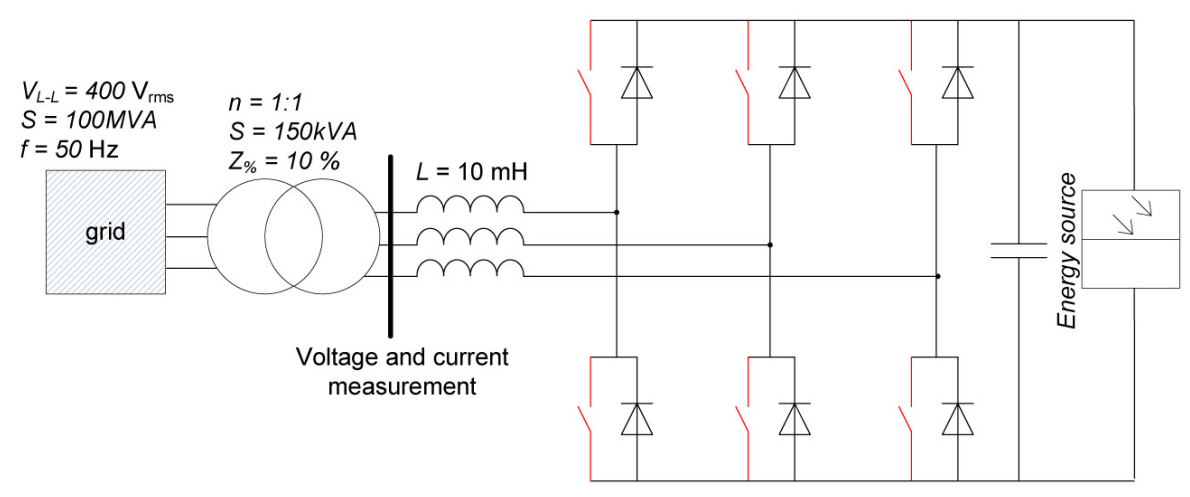

Figure 3. Two level voltage source inverter general structure 
i.e. they control the output voltage of the inverter and by adjusting its amplitude and phase, force the power flow into the network.

The first of considered herein control systems utilizes proportional-integral (PI) controllers operating in $\mathrm{dq} 0$ synchronous rotating reference frame, the second one is based on proportionalresonant regulators that are running in $\alpha \beta 0$ stationary reference frame [Timbus et al. 2006, Teodorescu. 2006. The general layouts of herein investigated control systems are presented in Figures 4-6. The different topologies result in various performance which is also manifested by current harmonics content.

In this paper, for calculation of the harmonic spectrum of current and voltage the simulations in a system presented in Figure 7 and Figure 8 were conducted using Matlab/Simulink software. Fourier transform was used to calculate the harmonic spectrum of currents and voltages on the systems with each control algorithm. Additionally the THD level was calculated based on each spectrum.

As can be seen in Figure 7 and Figure 8, the obtained results clearly indicate that the type of applied control algorithm affects the harmonics emission. In case of scheme based on PI controllers the resulting THD in current and consequently THD in voltage were lower than for inverter controlled by algorithm based on PR regulators (for PI: $\mathrm{THD}_{\text {current }}=1.8872, \mathrm{THD}_{\text {voltage }}$ $=0.021068$; for $\mathrm{PR}: \mathrm{THD}_{\text {current }}=2.7578 \%$, $\mathrm{THD}_{\text {voltage }}=0.028941 \%$ ).

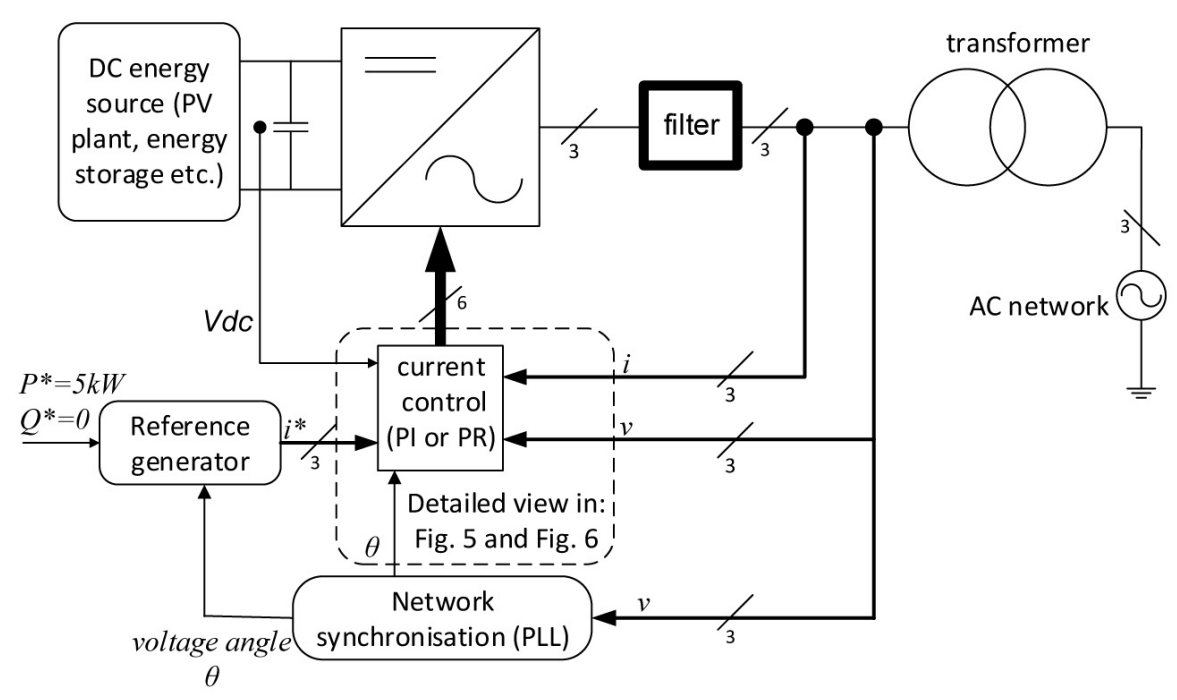

Figure 4. Analysed topology

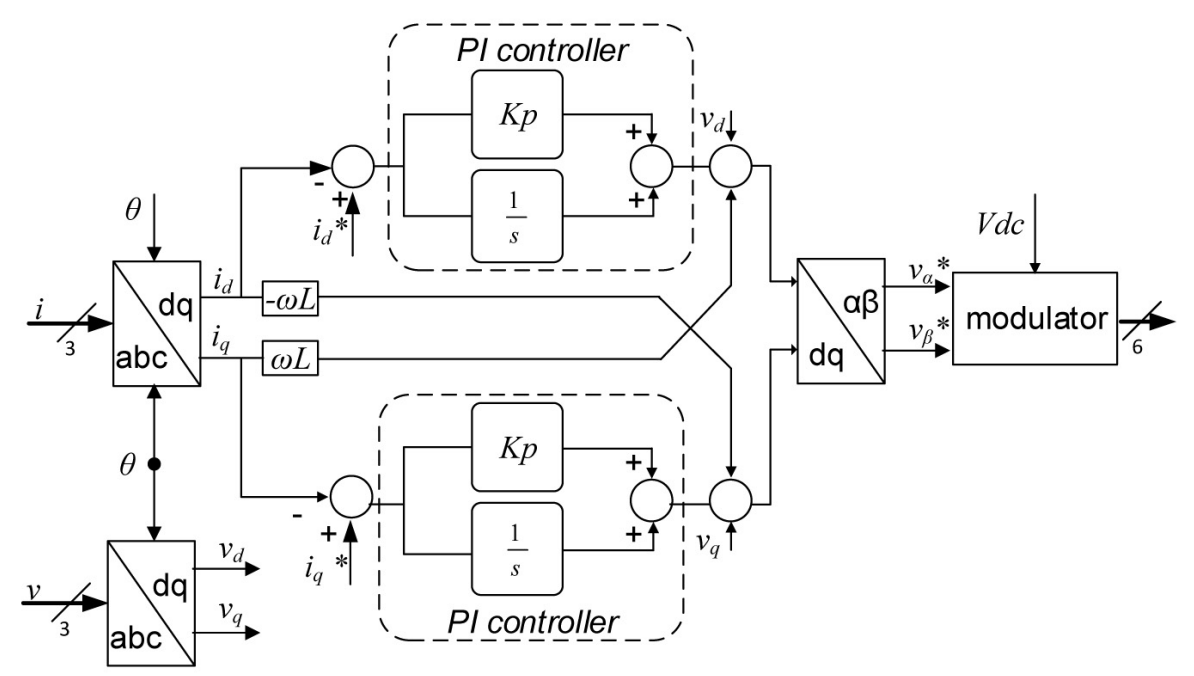

Figure 5. PI VOC 


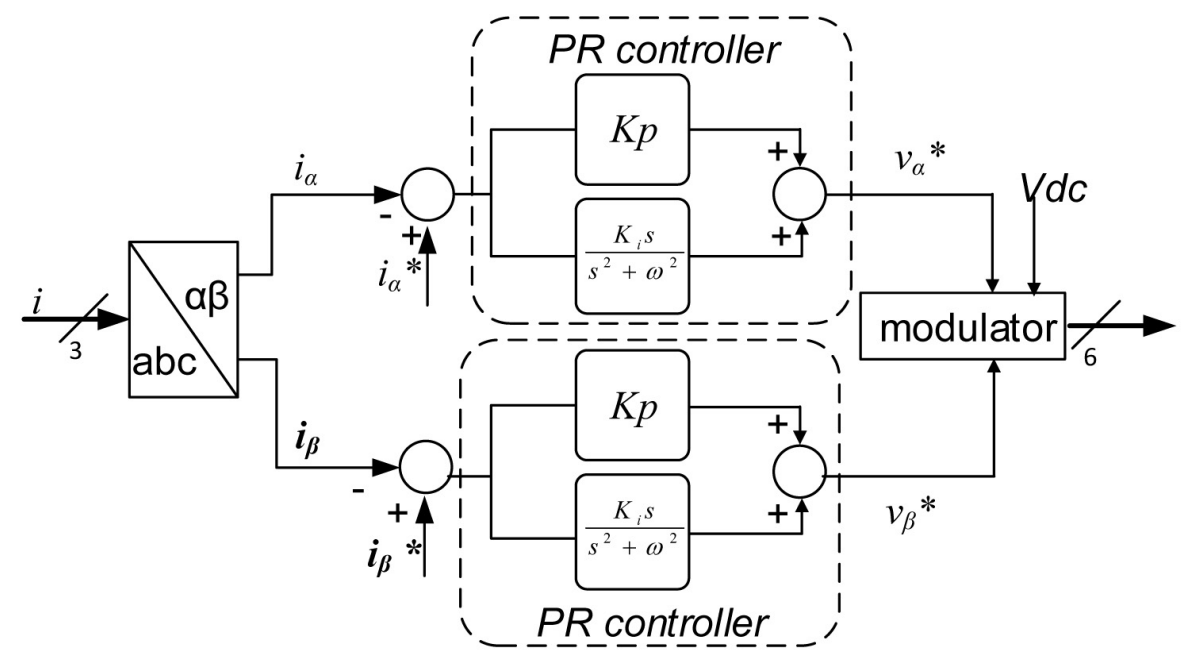

Figure 6. PR VOC
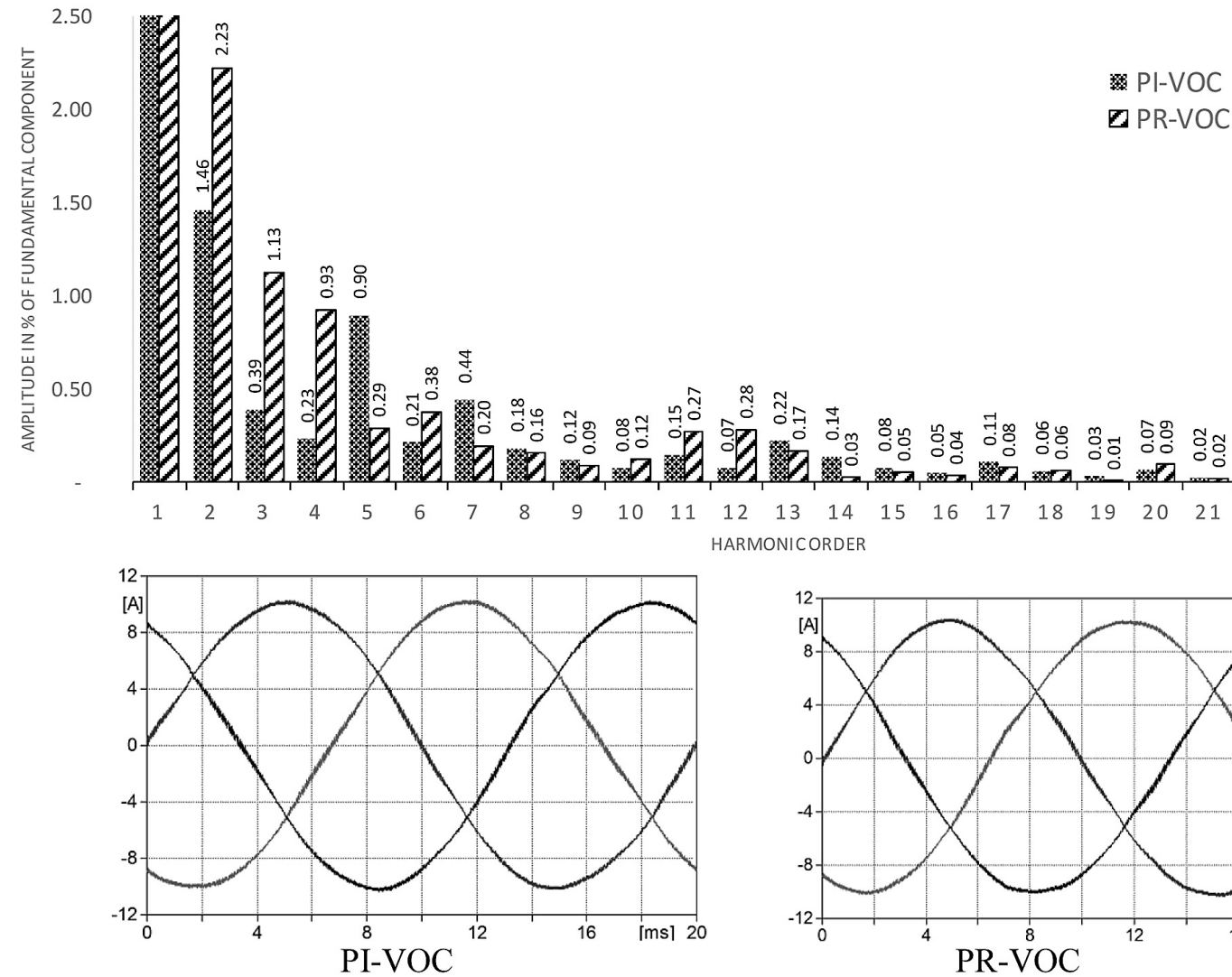

D PR-VOC

Figure 7. FFT of current and current traces 


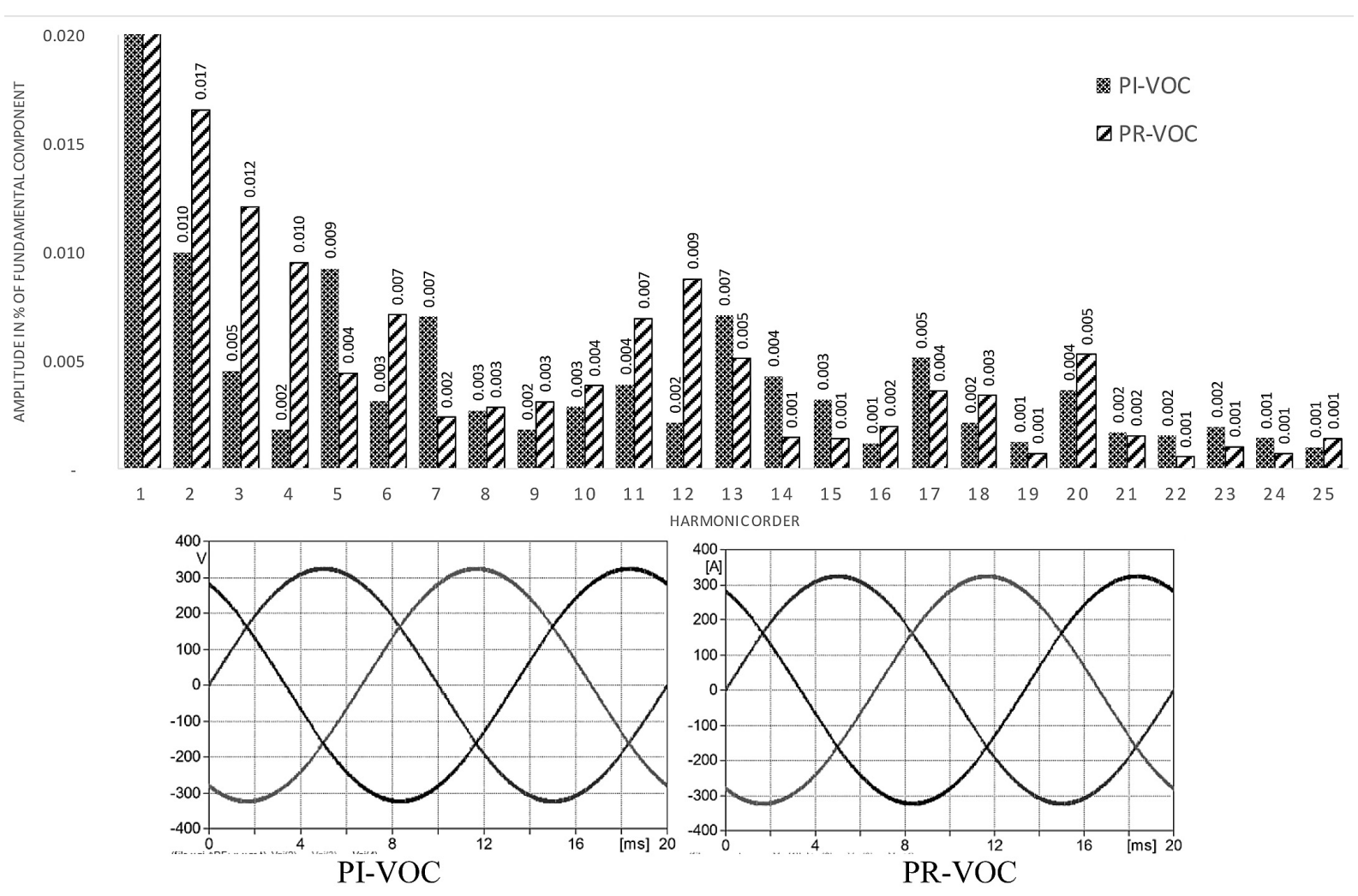

Figure 8. FFT of voltage and voltage traces

\section{HARMONICS AND ENERGY LOSSES IN POWER TRANSFORMERS}

As previously mentioned in section 2, one of the most common, adverse impact that harmonics have on various electrical equipment are losses. Those are usually manifested in increased heating but should be also accounted for at the design stage, which may increase the rating of e.g. cables or power transformers. All in all, harmonics related losses lead inevitably to higher material usage, cost and as a consequence negative influence on environment. In this paper the losses in power transformers are of a particular interest and are used to exemplify the existing problem. For this purpose the harmonic spectrum recorded in system presented in Figures 7-8 and its influence on power losses increase is analysed in this section.

The losses present in power transformers can be divided into few categories each of which is affected by presence of harmonics in current and voltage. No load losses are a consequence of transformer's iron core magnetization determined by hysteresis characteristics and are dependent only on supply voltage. If the supply voltage contains harmonic components, it will lead to no load losses increase. The factor that allows one to calculate per unit no-load loss change can be calculated according to formula (3) [IEEE 2008, Jagieła 2011]:

$$
K_{j}=\frac{1}{U_{N}^{2}} \sum_{h=1}^{N} \frac{1}{h^{0.6}}\left(\frac{U_{i}}{U_{1}}\right)^{2} \sum_{h=1}^{N} U_{h}^{2}
$$

where: $U_{N}-$ nominal voltage,

$U_{1}$ - fundamental voltage,

$h$ - harmonic order,

$\mathrm{N}$ - maximum significant harmonic order.

$K_{j}$ - is a ratio between losses when supplied from non-sinusoidal voltage source to losses when supplied from sinusoidal source.

Load losses $\left(\mathrm{P}_{\mathrm{LL}}\right)$ can be further subdivided into fundamental part caused by winding resistance and stray losses. First portion of stray losses $\left(P_{E C}\right)$ is caused by winding eddy-current circulating between strands or parallel winding circuits, independent of those stray power loss occurs in core, clamps, walls and other components of the transformer, this portion is referred simply as other stray losses $\left(P_{O S L}\right)$. Hence, total load loss $\left(P_{L L}\right)$ can be expressed as, IEEE [2008]: 


$$
\mathrm{P}_{\mathrm{LL}}=P_{R}+P_{E C}+P_{O S L}
$$

where: $P_{L L}-$ is total load loss, $\mathrm{W}$,

$P_{R}^{L L}$ is the resistance related conduction losses, W,

$P_{E C}$ - is the winding eddy current load loss, W,

$P_{\text {OSL }}$ - is the other stray loss, W.

The increase of eddy current loss and other stray loss due to non-sinusoidal current flow can be estimated based on formulas (5) and (6) presented in [IEEE 2008]. The resistive losses can be also affected by the harmonics in current if they increase the RMS value of the current, in this paper this influence is neglected due to the fact that the output active power of the converter is controlled and kept at the same level. Therefore, by combining equations (3), (5), (6) it is possible to capture the influence of harmonics to power transformer loss increase [IEEE 2008].

$$
\begin{gathered}
F_{H L}=\frac{\sum_{h=1}^{N}\left(\frac{I_{h}}{I_{1}}\right)^{2} h^{2}}{\sum_{h=1}^{N}\left(\frac{I_{h}}{I_{1}}\right)^{2}} \\
F_{H L-S T R}=\frac{\sum_{h=1}^{N}\left(\frac{I_{h}}{I_{1}}\right)^{2} h^{0.8}}{\sum_{h=1}^{N}\left(\frac{I_{h}}{I_{1}}\right)^{2}}
\end{gathered}
$$

where: $F_{H L}$-is harmonic loss factor for winding eddy currents $P_{E C}$,

$F_{H L-S T R}-$ is harmonic loss factor for winding other stray losses $P_{\text {OSL }}$,

$h-$ is harmonic order,

$I_{h}$ - is RMS current at harmonic "h" order,

$I_{1}$ - is fundamental RMS load current,

$N$ - is maximum significant harmonic order;

Table 1 presents the results of transformer losses increase calculations. They were based on the simulation outcome which is presented in Figure 7 and Figure 8. As can be observed, there is a visible difference in losses increase depending on the applied control method.

It has to be added that calculation of losses in transformers and reactor is very complicated and normally more sophisticated methods are employed for that purpose. These are usually based on magnetic FEM analyses. However, calculations based on formulas herein can give an approximate value of losses increase due to voltage and current distortion [Kefalas and Kladas 2010, Pan et al. 2012].

\section{FAULT RIDE-THROUGH IMPACT ON LIMITING THE POLLUTION}

Sample of FRT characteristics for Polish, Danish, German and Netherlands utility grids is presented in Figure 9 [Jarzyna \& Lipnicki 2013]. It should be interpreted in way that the wind farm should remain connected to the grid under the characteristics, e.g. in Poland when the voltage depression is as high as $85 \%$, the windfarm should be connected for $0.5 \mathrm{~s}$. However, for example during $20 \%$ voltage dip a wind farm should operate continuously. For small amounts of installed power produced by renewables, the sudden disconnection due to voltage dip is not of a concern. It is when the wind farm or photovoltaic plant are rated at hundreds of megawatts that such regulations are necessary mainly due to grid stability. However, if the disconnection happened, the loss of generation would have to be balanced by the conventional power plants that will contribute to increased pollution. This is why test methods exists that allow assessing the response of renewables coupled via digitally controlled power electronic converters during various grid disturbances [Zieliński et al. 2014].

Let us then consider the scenario in which these requirements are not imposed on the wind farms or other renewables in case of $100 \mathrm{MW}$ wind farm installed in Poland, operating at its maximum power which is subjected to voltage dip no larger than $20 \%$. In this case, it should remain operating indefinitely if the FRT capability is required by the operator and could be shut down even immediately after dip detection. The carbon dioxide $\left(\mathrm{CO}_{2}\right)$ emission per MWh produced by thermal power plants in 2010 was estimated at 0.5 tons of $\mathrm{CO}_{2}$ per MWh [European Commission 2013]. Taking into account that the windfarm may deliver some reactive power to support the grid voltage recovery, then the output active

Table 1. Losses increase factors for different types of applied converter control algorithms

\begin{tabular}{|c|c|c|c|}
\hline & $\begin{array}{c}\text { PR-VOC } \\
\text { control }\end{array}$ & PI-VOC control & $\begin{array}{c}\text { Losses } \\
\text { increase } \\
\text { reduced by: }\end{array}$ \\
\hline$F_{\text {HL }}$ & 1.008415749 & 1.006753825 & $0.16480544 \%$ \\
\hline$F_{\text {HL-STR }}$ & 1.000960727 & 1.000603173 & $0.03572108 \%$ \\
\hline$K_{j}$ & 1.000432248 & 1.000432188 & N/A \\
\hline
\end{tabular}




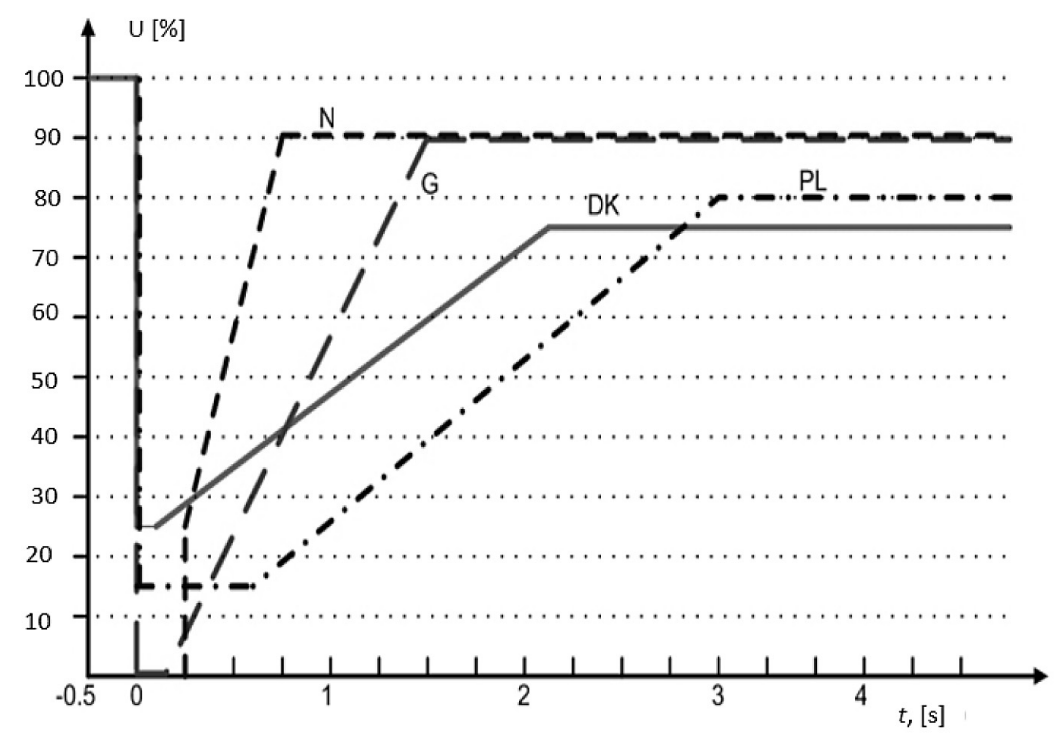

Figure 9. Requirements of European grid operators for wind farms operation during voltage dips [Jarzyna \& Lipnicki 2013]

power is assumed to be reduced to $80 \mathrm{MW}$. At this power level every second of wind farm power generation absence would result in $\mathrm{CO}_{2}$ emission as high as $11.1 \mathrm{~kg}$ if we assume that this energy gap is balanced by the thermal power plants.

The above-mentioned simple discussion is just an example that the coordination of renewables integration with the grid imposed by regulations or otherwise may potentially lead to greenhouse gases emission reduction. In the presented example, the assumed $\mathrm{CO}_{2}$ emission is an average for all kinds of thermal power plants. This means that the potential $\mathrm{CO}_{2}$ emission could be even higher e.g. in case of older coal fuelled power plants.

\section{CONCLUSIONS}

The simulation and calculation results show the difference between the losses increase depending on the applied inverter control. This difference will change depending on the system condition such as load current, equipment rating etc. However, it is evident that the power transformer losses can be reduced indirectly with use of control for power electronic converter. In certain cases, especially when inverter current is significant such reduction may lead meaningful savings and energy quality improvement. It is noteworthy that this paper focuses only on two fundamental control methods and the further harmonics reduction could be achieved using other algorithms out there.
Fault ride-through is another environmental aspect related to power electronics which was described in this paper. Based on the literature, it was shown that regulations imposed by grid operators that require inverter to stay connected to the grid during faults can prevent unnecessary additional greenhouse gases emission and pollution.

\section{REFERENCES}

1. European Commission 2013. EU Energy, Transport and GHG Emissions, Trends to 2050; http:// ec.europa.eu/energy/sites/ener/files/documents/ trends_to_2050_update_2013.pdf

2. IEEE 2008. IEEE Recommended Practice for Establishing Liquid-Filled and Dry-Type Power and Distribution Transformer Capability When Supplying Nonsinusoidal Load Currents. In: IEEE Std C57.110-2008 (Revision of IEEE Std C57.110-1998), pp. 52.

3. IEEE 2013. IEEE Recommended Practice and Requirements for Harmonic Control in Electric Power Systems. In: IEEE Std 519-2014 (Revision of IEEE Std 519-1992), pp. 29.

4. Jagieła K., Rak J., Gała M. and Kępiński M. 2011. Straty mocy $w$ transformatorach energetycznych zasilających dużych odbiorców przemysłowych. Elektroenergetyka: współczesność i rozwój, 46-56.

5. Jarzyna W. 2011. Terms of the turbine and generator choice of wind power stations. Rynek Energii, 4, Aug., 102-106. 
6. Jarzyna W. and Lipnicki P. 2013. The comparison of Polish grid codes to certain European standards and resultant differences for WPP requirements. Power Electronics and Applications (EPE), 15th European Conference on, Lille, 1-6.

7. Kefalas T.D. and Kladas A G. 2010. Harmonic impact on distribution transformer no-load loss. IEEE Transactions on Industrial Electronics, 57(1), 193-200.

8. Pan C., Kong L., Zhenxin L., Zheng Q. and Wang Z., 2012. Analysis based on improved method for transformer harmonic losses. Energy Procedia, 16, 1845-1851.

9. Teodorescu R., Blaabjerg F., Liserre M. and Loh P.C., 2006. Proportional-resonant controllers and filters for grid-connected voltage-source converters. In Electric Power Applications, IEE Proceedings, 153(5), 750-762.

10. Timbus A.V., Teodorescu R., Blaabjerg F., Liserre M. and Rodriguez P. 2006. Linear and nonlinear control of distributed power generation systems.
In: Industry Applications Conference, 41st IAS Annual Meeting. Conference Record of the 2006, IEEE, Vol. 2, 1015-1023.

11. Yaramasu V., Wu B., Sen P.C., Kouro S. and Narimani M., 2015. High-power wind energy conversion systems: State-of-the-art and emerging technologies. Proceedings of the IEEE, 103(5), 740-788.

12.Zieliński D., Jarzyna W., Filipek P. 2014. Method for testing converter network of electricity generating source, involves controlling source by first control bus and processing control signals using analog to digital converter, and transmitting signals to amplifier by control bus. Patent Number: PL407835A1, Patent Assignee: Politechnika Lubelska.

13. Zieliński D., Lipnicki P., Jarzyna W., 2015. Synchronization of voltage frequency converters with the grid in the presence of notching. Compel - The International Journal For Computation And Mathematics In Electrical And Electronic Engineering, 34(3), 657-673. 